\title{
Una Batalla entre Antiguos y Modernos
}

\author{
Juan Valera y Carlos Reyles
}

\author{
It is almost impossible to understand \\ the art of a generation younger than one's \\ own. \\ William Butler YeAts, A Packet \\ for Ezra Pound.
}

$\boldsymbol{D}^{E}$ E gustibus non est disputandum: verdad axiomática. Y verdad, como tantas otras, mil veces atropellada con provecho para el mundo. Porque al fin la disputa puede ser fragua en que se temple la belleza. Prueba de ello son La raza de Cain y El embrujo de Sevilla, novelas que escribió Carlos Reyles después de su polémica con Juan Valera, y las dos de un valor apenas pronosticado por las que motivaron la discusión. Guillot Muñoz, en st apreciable aunque sobradamente laudatorio Estudio sobre Carlos Reyles, 1 TorresRioseco, en reciente y menos panegírico examen, 2 y el propio Reyles 3 son los que con más detenimiento han tratado este episodio en la vida del uruguayo. Pero es para todos incidental, resultando necesariamente superficial la ojeada que le echan. $Y$ por muchos respectos merece un análisis algo más extenso esta batalla entre antiguos y modernos: fué muy grande el prestigio de los contendientes. Influyó enormemente, aunque de modo indirecto, en la evolución artística de Carlos Reyles. Refleja un momento de su pensamiento sobre la novela, y precisamente en una etapa muy crítica de su historia. $Y$, acaso ante todo, alguna vez llega a tocar, siquiera al soslayo, las mismas bases de la actitud estética. Me faltan alas y 
espacio para ir al alcance de la multitud de implicaciones que se desprenden de este microcosmos teórico, pero el lector las cazará al vuelo.

Joven, y con la arrogancia de sus pocos años, en septiembre de 1896 Reyles firma las páginas "Al lector" que sirven de prólogo al Primitivo, 4 primera de las que tuvo el capricho de llamar sus academias, y que hacía siglos que venían llamándose novelas cortas. Capricho, pero capricho ya indicativo. Porque el nuevo nombre simboliza el nuevo sesgo que Reyles se propone introducir en la novela, sesgo definido en esas páginas "Al lector" que vienen a ser como manifiesto de una revolución: siendo ya otro el mundo, no cabe ya en los antiguos moldes artísticos. Se está sintiendo la necesidad de otro arte "que no permanezca indiferente a los estremecimientos e inquietudes de la sensibilidad fin de siglo, tan refinada y compleja, y que esté pronto a escuchar los más pequeños latidos del corazón moderno, tan enfermo y gastado. En substancia: un fruto que sea hijo legítimo de su tiempo". 5 En Esspaña la novela no ha cambiado desde el siglo XVI. Sigue escribiéndose en las fórmulas picarescas y costumbristas que, a pesar de su belleza, son muy limitadas y superficiales. para expresar los matices espirituales de la nueva edad. En otros países los autores se esfuerzan constantemente por extender el campo de la novela en forma y fondo, procurando adivinar el arte del porvenir. Las almas complejas, sensibles, intelectuales, van a Tolstoy, a Ibsen, a D'Annunzio, a Huysmans, en busca de una creación que responda a sus aspiraciones. Y pues el número de estos espíritus delicados aumenta de día en día en España y América, ha llegado la hora de dedicarse a ellos en castellano. Esto es lo que Reyles piensa hacer. Otros lectores, los que pidan a las obras de imaginación "mero solaz, un pasatiempo agradable, el bajo entretenimiento que diría Goncourt", llamen a otra puerta. "No quiero entretener a nadie... Ia novela noderna debe ser una obra de arte tan exquisito, que afine la sensibilidad con múltiples y variadas sensaciones, $y$ tan profundo, que dilate nuestro concepto de la vida con una visión nueva y clara". 6 
Dos, pues, son los puntos suscitados por Reyles: la necesidad de dejar las formas castellanas, buscando el arte del porvenir en la literatura de otros países; y la repudiación del entretenimiento como fin de la literatura. Hay que tener mucho valor y mucha confianza para predicar la fórmula que nos haga olvidarnos de las antiguas, y más para pretender encarnarla en obra propia, como hace Reyles en Primitivo. Más le habría convenido dejar su pronunciamiento para La raza de Caín. Primitivo mal puede sostener el peso de tan solemne prefacio, no obstante sus méritos nada despreciables.

II

Bastante evidentes estos méritos, en efecto, para que Juan Valera, reconociéndolos, y echando de ver por el prólogo que se las había con un hombre no menos peligroso que presumido, enviase carta a El Correo de España 7 de Buenos Aires sobre la obra del novel autor. Valera empieza ostensiblemente con una critica de Los raros de Darío, libro publicado años antes. Pero en seguida se nota que está apuntando a Carlos Reyles. Como en otras infinitas ocasiones, habla de la universal imitación de los movimientos artísticos de Francia, tendencia exageradísima en Hispanoamérica. No es que condene toda imitación. Al contrario, concede que "dentro de cierto límite y refrenado por la prudencia y el buen gusto, el afán de lo nuevo tal vez atine a crear algo nuevo; tal vez lo extraño, lo exótico, lo peregrino discretamente tomado y diestramente adaptado a la literatura propia, logre hermosearla con galas y adornos que nunca tuvo..." 8 Sabido es que en el caso de Rubén Dario, Valera hasta se permitió aplaudir algunas imitaciones, admitiéndolas como verdaderas aportaciones a la lira castellana. Sólo impone un freno: "Ya que las castañuelas se toquen, deben tocarse bien". 9 Esto para Valera implica, en primer lugar, no dejarse influir por los vaivenes de la moda. "Convertir en artículos de moda los milagros divinos, las creaciones inmortales de las musas, es, a mi ver, la más ruin y espantosa de todas las herejías en la religión del arte". 10 Bien que un autor -al fin inescapablemente hombre de su época- refleje su momento histórico en lo que escribe. Valera no niega que en cada siglo hay tendencias y corrientes distintas de las anteriores: "Lo que niego es que deba nadie buscar la corriente o la tendencia para lanzarse en ella, premeditada y reflexivamente. Si tal hace, se 
expone a caer en lo amanerado, afectado y falso... En el caso del Sr. Reyles... hay la premeditación reflexiva y la voluntad de ir por dicha corriente..."11

Esto, pues, en cuanto al primer punto de Reyles. Ahora Valera se mete con él respecto a los fines del arte. Le duele no sólo que Reyles sacrifique el propio estro siguiendo una moda, sino que haya escogido una moda tan detestable: "Francamente, yo he creído siempre y sigo creyendo, que una novela, corta o larga, debe ser libro de pasatiempo y solaz, debe elevar y no consternar el ánimo, debe, cono decía Aristóteles, purificar las pasiones, esto es, que, por muy trágica que sea, el terror y la compasión que inspire han de estar purificados, han de producir en nosotros el deleite estético y no la pena, han de serenar el espíritu y no perturbarle, humillarle o deprimirle". 12 Es decir, que Valera acepta el elemento trágico; sólo difiere en su concepto de lo que puede constituir ese elemento. $Y$, sea o no una actitud frívola, insiste en pedir a la creación literaria cierto optimismo: "Conviene que aparezca, siquiera en último término, un supremo desenlace providencial y dichoso". 13 Este desenlace lo ve en la obra de los trágicos griegos, no en la nueva escuela. Abomina del determinismo de ésta, que para él, en cuanto hombre, quita a la vida todo sentido, y, en cuanto crítico, quita a la tragedia todia esa grandeza que resulta del conflicto entre el libre albeđrío y los poderes que lo contrastan.

Por ambas partes, pues, Valera se muestra contrario a la doctrina de Reyles. Califica de "seguir la moda" el hacer el escrutinio reflexivo de lo que se escribe para adoptarse una actitud, y desaprueba la materia y el punto de vista de los llamados "artistas del porvenir". Debajo se siente constantemente el escozor del español herido en su amor propio, la preocupación patriótica que induce a Valera a la inconsecuencia de objetar que: "De todos modos, prescindiendo de que sea buena o mala, me parece que la escuela a la moda que sigue el Sr. Reyles no es tan ignorada o tan no seguida en España como el Sr. Reyles supone". 13

III

Reyles no replicó a esta crítica de Primitivo, acaso porque, estando en España al publicarse en Buenos Aires, no llegase a cono- 
cerla. No sería porque la encontrase muy favorable. Al fin lo único bueno que encuentra el crítico es el mal empleado talento del joven novelador y ciertos pormenores de su obrita. Ha sido un error creer que había sido halagüeño 14 el juicio de Valera en que nos hemos detenido aquí precisamente porque anticipa casi todos los argumentos del artículo que suscitó la polémica.

Al publicar El extraño, segunda de las academias, Reyles no hace más que refundir el prólogo de Primitivo, añadiendo expresiones de respeto por el arte de Pérez Galdós y Pereda, arte que sin embargo sigue pareciéndole poco apto para cristalizar la nueva sensibilidad, y muy epidérmico para satisfacer nuevos deseos de penetrar hasta el fondo de las almas. Esta vez, sin duda por lo de epidérmico, Valera realmente se incomoda. A fuer de buen diplomático, hizo la crítica de Primitivo con habilidad suficiente para que al poco cauto le pareciese favorable una sentencia que en realidad deja muy poco a la pobre novela. En su artículo El extraño, última moda de París, publicado en las páginas de El Liberal de Madrid, ya no deja lugar a dudas acerca de su verdadera opinión, desatándose en lo que son para él, de suyo tan benévolo, párrafos harto crueles - aunque harto donosos también, fuerza es confesarlo; porque no sería esto lo que menos hiriese al candoroso revolucionario. Fuerza es confesar también que Valera, de su parte, añade muy poco a las ideas expuestas en El Correo de España. En cambio ahora desarrolla un pensamiento apenas vislumbrado alli, el de la imposibilidad del progreso en literatura, o al menos de un progreso que dependa de la cronología, y que ineludiblemente sobrepuje a las grandes obras de antaño. Este es el eje sobre el cual gira la polémica que surge a raiz del artículo de Valera.

En su crítica de Primitivo, Valera ya había dejado caer una palabra de propósito, al hablar del afán de novedades de las letras francesas: "De aquí que en lo que no cabe adelanto ni progreso, que en lo que es permanente y está por cima de las variaciones y caprichos de la moda, que en la poesía, en su más amplio significado, se inventen en París, cada dos o tres años, nuevos usos..." $15 \mathrm{Pe}-$ ro dejó sin desenvolver esta noción, que viene a ser principal en el estudio sobre El extraño. Explica la antipatía con que Valera miraba las modas y escuelas literarias: "En lo científico, el imitar y el alcanzar se comprenden, porque en lo científico cabe y hay progreso; 
pero en lo puramente literario y artístico no se progresa nada. El progreso no trae escultor que valga más que Fidias, ni lírico mejor que Píndaro, ni trágico mejor que Sófocles... Considero, pues, absurda alucinación la de creer que las artes del dibujo y de la palabra, cuyo fin es crear la belleza, vayan perfeccionándose con el tiempo... 16 Nadie ha escrito hasta ahora una más hermosa novela que el Quijote, aunque yo no niego que podrá un día escribir alguien otra mejor novela; pero esta mejor novela no lo será porque se haya progresado, sino porque Dios... hará que nazca... un novelista más ingenioso, más profundo y más ameno que Miguel de Cervantes. De todos modos, la mejor novela que hoy se escriba, no lo será porque se funde en una estética recién descubierta, y porque se ajuste a determinados procedinientos a la última moda de $\mathrm{Pa}$ rís..." 17

En cuanto a la tan decantada literatura del porvenir, claro que no puede faltar, aunque no será la que por su mayor penetración haga olvidar la de otras edades: "Se cae de su peso que la literatura, reflejo de creencias, doctrinas, costumbres y leyes..., varía tan a menudo como varían todas estas cosas en el seno de la sociedad humana. En este sentido, la literatura del siglo XVIII, con relación a la del siglo XVII, fué literatura del porvenir, y la del siglo XIX lo fué con relación a la del siglo XVIII...; pero no es esta perogrullada lo que quiere expresarse cuando se habla hoy de literatura del porvenir. Lo que quiere expresarse es la aparición de escritos tan profundos y sutiles que los de Homero, Dante, Virgilio, Ariosto, Shakespeare..., sea fruslería insubstancial, superficial y epidérmica, que de tal la califica el señor Reyles, comparado con lo que ya se va' escribiendo..." 19

Habiendo así aclarado su posición frente al primer punto suscitado por Reyles, Valera vuelve al problema de los fines del arte: "Lo que me choca más es el propósito de que las novelas, cuentos, academias o como quierah llamarse, no se han de escribir para deleitar..., sino para mortificar, aterrar y compungir a los lectores..." 19 Con la añadidura de que tampoco el muy celebrado análisis de hogaño es nuevo, no obstante Huysmans y D'Annunzio. En cuanto al estudio del sensualismo, por ejemplo, la Oala de Ezequiel puede dar cinco y raya a Nana, y en lo tocante al hastío fin de siglo de Julio Guzmán, el extraño de Reyles, ya el Eclesiastés se le adelantó "en unos tres 
mil años". Otra vez, el único hueso sano que le queda a Reyles es el de su mérito indisputable y valer literario. Por lo demás, ya se ve que aparte el mayor desenvolvimiento del tema de la negación del progreso artístico, Valera no ha hecho mucho más que reiterar con libre desenfado los reparos que ya le había puesto a Primitivo. No extraña que Reyles, puesto como chupa de dómine, se haya creído en el deber de sincerarse frente al público, lo que hace con no menos dignidad que vigor en el mismo Liberal, fecha de 26 de septiembre de 1897 , en carta titulada "La novela del porvenir", y dirigida a don Juan Valera. 20

IV

Reyles empieza difiriendo de Valera sobre los fines de la literatura: "En mi prólogo, tan llevado y traído, de mi segunda academia, decía que la novela moderna debe ser obra de un arte tan exquisito, que afine la sensibilidad con multiples y variadas sensaciones, y tan profundo que dilate nuestro concepto de la vida con una visión nueva y clara, añadiendo que no me proponia entretener, sino hacer sentir $y$ hacer pensar por medio del libro lo que no puede sentirse en la vida sin grandes dolores, lo que no puede pensarse sino viviendo, sufriendo y quemándose las cejas sobre los áridos textos de los psicólogos...

"Y bien; al formular lo dicho, me parecía, y sigo creyéndolo, que interpretaba, no sólo las vagas aspiraciones de los escritores nuevos, sino también los sentimientos de una gran parte del público, la más culta, que no le pide a la novela mero solaz y agradable pasatiempo, sino impresiones y sensaciones más profundas y más elevadas, semejantes a las que produce El anillo del nibelungo, El Fausto, La Divina Comedia... Efectivamente; no sin grande impropiedad y notoria injusticia, llamáranse obras de mero solaz y pasatiempo a Crimen y castigo, Germinal o a Fortunata y Jacinta... las cuales... nos hacen vivir una vida más intensa y completa que la vida misma. ..."

Reyles luego vuelve al primer punto, la cuestión del progreso, sobre el cual tampoco le convencen los argumentos de Valera: "Hasta cierto punto cabe negar que en lo puramente literario y artístico no existe progreso, o mejor aún, que el progreso no es continuo o indefinido. Un arte o género progresa mientras duran las especialísimas 
causas y condiciones que lo inspiran y sustentan... No variando el medio conveniente para la vida de un arte, o mejor dicho, para la vida de un momento del arte o de un género literario cualquiera, ese arte o este género se perfecciona hasta producir la más bella flor... Para la novela, el medio ha sido siempre favorable, y por eso no ha hecho otra cosa que subir de punto en valor desde que nació hasta nuestros días, teniendo, como es natural, en cada época su florecimiento característico". Reyles concede, sin embargo, "que a ninguna época le es dado sobrepujar, ni siquiera igualar con otras de artificio, las obras que fueron espontánea y legítima expresión de otra época".

En cuanto a la naturaleza del progreso que ve en la novela, encuentra que "la novela ha tendido siempre a penetrar cada vez más hondo en el alma del hombre y en el alma de la Naturaleza... tampoco es menos cierto que a toda hora se ha ido afirmando cada vez más en la tendencia de huír del mero entretenimiento, de la fábula frívola... Hoy juzgamos que la novela mejor es la que produce sensaciones más hondas y duraderas, no la que nos divierte en mayor grado. La excelencia de la novela moderna sobre la antigua consiste en eso, y en eso también consiste la superioridad de la novela francesa y de la rusa sobre la española..." Reyles enumera algunos florecimientos característicos, y en cada etapa ha de suponerse que ve un paso en el progreso del género: "libros de caballería, la novela pastoril, picaresca, costumbrista y romántica, hasta el realismo, naturalismo y la novela psicológica..."

Años después Reyles expuso más claramente este concepto de la evolución de la novela : 21 "Antaño lo que preocupaba al novelista eran la invención y la amena narración de una fábula emocionante en la que intervenían, para llevar a buen término estupendas aventuras, seres que muy poca o ninguna relación tenían con los de carne y hueso. Luego, la pintura de seres tomados del natural o instalados en un ambiente histórico o vivo dieron margen a la novela picaresca, la histórica, la costumbrista. Más tarde a la exposición de los conflictos sucede el análisis, no de los conflictos, sino de los estados de alma y los espejismos interiores; por último aparece la psicología arbitraria: en vez de la realidad las posibilidades de ella y el campo infinito de las alteraciones de la personalidad bajo la acción de los poderosos reactivos del tiempo y los sueños, los lapsus de la memoria, las intermitencias del corazón. El asunto, la intriga, las peripecias, 
lo que juzgábamos realmente novelesco pierde su valor, deja de interesarnos así como la realidad, que antes buscábamos hasta intentar convertir la novela con el realismo y el naturalismo en copias de aquélla, olvidando que la novela, por ser arte, es creación". 22

Parafraseando, se diría que la novela en su evolución ha pasado desde lo que está por debajo (o por encima) de lo real, hasta ocuparse de lo real, y, por último, de lo que está por encima (o por debajo, según las miras) de lo real. Puesta la cuestión en este terreno, y haciendo caso omiso del concepto de progreso, es indudable que Valera hubiera coincidido con Reyles. Sólo que siempre hubiera visto cambios en vez de progresos, mientras que para el uruguayo, cambio y progreso a la larga vienen a ser sinónimos. 23

A la carta de Reyles, Valera repuso con otra que tituló "Sobre la novela de nuestros días", 24 en la que reafirma que "quien entiende que hay tales modas $y$ tales progresos, escribe mucho peor que si entendiese lo contrario, corta las alas de su ingenio en vez de alargarlas y darles fuerzas, pierde parte de su originalidad, cuando no la pierde toda y se expone a caer en lo falso, en lo amanerado y en lo extravagante". 25 Pero no añade gran cosa a lo ya dicho, y Valera bien pudiera haber dejado su empeño aquí. No hizo tal. Elaboró su pensamiento aún más en una serie de cuatro artículos que forman el estudio "Del progreso en el arte de la palabra". 26 Interesa como siempre la dialéctica de Valera, la elegancia y destreza con que esgrime las ideas. Pero otra vez hay que reconocer que poco adelanta con este nuevo derroche de ingenio, y que nada pierde el más sobrio Reyles. Unicamente es notable que Valera logre, por medio de una imagen muy ingeniosa, identificar los dos puntos, antes separados, de moda y progreso por un lado, y por otro, de la materia del arte. Se figura que Pericles resucitado y guiado por un sabio de los más profundos del dia, visita un gabinete de figuras de cera: "Pues no digamos nada si el sabio da cuerda a las figuras, y... se sueltan a andar... Y aun será mayor el asombro de éste, cuando su sabio guía toque ciertos resortes, abra ventanillas en el vientre y en el pecho a las figuras mencionadas... Pericles tendrá que confesar entonces que esto es exquisito y profundo... Lo que no confesará, 
Jo que negará a pies juntillas, es que sea bella arte semejante diablura". 27 Seguirá prefiriendo las esculturas de Fidias, por epidérmicas que sean, rehusándose a admitir que se haya progresado un ápice artísticamente, por mucho que se haya adelantado en materia científica.

vI

Hasta aqui Reyles y Valera. Pero ya a estas horas varias voces se mezclaron al concierto y lo que empezó como solo de Valera se hizo coro, aunque no unísono. Valera mismo así lo confiesa: "Lo que se me ocurrió decir hace tiempo sobre las novelitas del señor Reyles, ha dado ocasión o motivo a una extensa polémica, en la que han tomado parte el mismo señor Reyles, la señora doña Emilia Pardo Bazán y los señores don Jacinto Octavio Picón y don Eduardo Benot". $28 \mathrm{Y}$ a estos nombres hay que añadir los de Leopoldo Alas $29 \mathrm{y}$ Eduardo Gómez de Baquero.

Muy temprano la autorizada pluma de éste tributó a Reyles la atención de que, en el juicio de todos, era merecedor. Es un error suponer que el crítico haya dado fin a la polémica con un fallo favorable para Reyles. Gómez de Baquero se inclinaba en efecto al lado del uruguayo, aunque no sin aceptar muchos de los argumentos de Valera. Pero no sólo no dió fin al certamen, 30 sino que expuso sus opiniones antes de escribir Valera "Del progreso en el arte de la palabra", y antes de meter baza contendientes tan insignes como Emilia Pardo Bazán y Eduardo Benot.

"Andrenio", igual que Valera, da una reseña de Primitivo meses antes de examinar El extraño. Es de notar que, más bien que favorecer gran cosa al autor de las academias, se aproxima mucho al juicio de Valera, y hasta anticipa una parte de las objeciones que éste puso a la segunda de estas obritas. Habiendo comentado en su artículo las novelitas Pandereta de Luis Orrego Luco y Suprema ley de Federico Gamboa, encuentra que Primitivo tiene muchos puntos de contacto con ellas: "Parece deducirse de ahí que en los pueblos de la América española subsiste cierta comunidad intelectual y artística que se traduce en sus concepciones literarias. Pero, evidentemente, aunque sea poco grato para nosotros, españoles, el reconocerlo, esta comunidad que a ellos les mantiene unidos en espiritu - al menos en el terreno de 
las letras- no les impulsa hacia su antigua Metrópoli, sino hacia otros centros de cultura y de inspiración literaria hoy más florecientes. La América española va volviéndose América latina, como la llaman en París. Su Metrópoli intelectual no parece ser España, sino Francia". 31

Cierto es que, en vez de incomodarse con este motivo, Gómez de Baquero lo constata fría aunque sentidamente como un fenómeno observable. Pero no por eso deja de acudir a la defensa de la patria tan altivamente desdeñada: "El señor Reyles no debe haber estudiado bien nuestra literatura contemporánea... Puede afirmarse que nuestros novelistas de hoy se parecen más a los cultivadores contemporáneos de este género en otros pueblos, que a sus predecesores. Verdad es que estos escritores han tenido el buen gusto de no plagiar a los extranjeros, y han sabido mantenerse españoles, aunque no españoles del siglo XVI, sin sustraerse por eso al influjo de las ideas estéticas reinantes". 32 Se ve que "Andrenio" sabía zurrar la badana como el que más. Pero Reyles no contestó, más que para esclarecer un punto lingüístico suscitado por el crítico. $33 \mathrm{Y}$ tampoco habló más tarde cuando éste, al tratar de $B e b a$, volvió a aludir al ascendiente ejercido pór París en las letras americanas. 34 Fiel creyente en el progreso literario, le parecía fuera de duda no ya poder, sino hasta deber, imitar lo nuevo sin guardar miramientos a nada ni a nadie. Sólo cuando Valera quiso impugnar ese procedimiento filosóficamente, dudando que por ese camino se llegase a la gloria, acudió a defender sus principios. $Y$ aun entonces vindicaba, más que a sí mismo, a una idea.

Hemos visto de qué modo la vindicaba. Gómez de Baquero concede la justicia de su actitud, no sin algunas reservas: "Como sucede, por lo general, en estas polémicas literarias, que no están sujetas al rigor de una discusión científica, ambos contendientes tienen su parte de razón y uno y otro emiten proposiciones que parecen exactas y acertadas. A mi entender, la opinión del señor Reyles es la que más se aproxima a la verdad, aunque acaso lleve ventaja en el debate el señor Valera... Pero no siempre tiene razón el que con más habilidad razona, y eso le sucede, a mi juicio, en el presente caso, al insigne autor de Pepita Jiménez". 35 Comprende que los americanos vayan a buscar modelos fuera de España, aunque insinúa que sería mejor conservar, al hacerlo, el sello propio: "Mucho mejor 
sería para nosotros, y acaso para los americanos de nuestra raza, que España siguiese siendo la metrópoli intelectual de sus antiguas provincias del Nuevo Mundo. No lo es, y ante el hecho sirve de poco la dialéctica. Estas primacías intelectuales no se ganan por títulos históricos, ni por los meros vínculos de consanguinidad y de raza. Requieren una superioridad de cultura que, no poseemos con relación a otros pueblos de Europa, y no podemos censurar en justicia a los hispanoamericanos porque busquen inspiración en esos pueblos. Nosotros la buscamos también, y debemos buscarla, puesto que no sería racional que nos privásemos de participar de los beneficios de la ajena cultura por espíritu de casta, o por exagerado amor a tradiciones muertas. $Y$ podemos hacerlo sin afrancesarnos, ni germanizarnos, ni cosa parecida..." 36

Espada de dos filos es el juicio de Gómez de Baquero sobre el deleite como fin de la literatura. Porque, si bien parece rechazar, al menos en parte, la opinión de Valera, implícitamente coincide con él en oponerse al proceder de los que deliberadamente se dedican a cultivar lo que Valera llama la moda: "Cuanto a que tenga la literatura el mero fin de deleitar, aun concediéndolo, hay que reconocer que este deleite es de una índole particular... El deleite literario consiste en estimular la vida imaginativa... Para comunicar este estímulo se necesita haberlo sentido: de ahí que la literatura sea, ante todo, al menos considerada subjetivamente, expresión de algo comprendido y sentido, y no combinación artificiosa, ideada en vista de los gustos de un público y de su posible deleite". 37

Con Valera, "Andrenio" - reconociendo que el personaje de Julio Guzmán está calcado sobre la novela francesa contemporánearehusa admirarse como su creador de la novedad del tipo que representa: "No es tampoco fruto exclusivo de nuestra civilización la carta de los partidarios del Unico de Stirner. El hedonismo individualista se descubre ya en los tiempos más remotos, y vemos huellas de él en las más antiguas literaturas del Oriente. Se puede repetir, a propósito de esto, como de tantas otras cosas que a las veces nos sorprenden y nos alarman, que nada hay nuevo bajo la faz del sol. Y ahora, como siempre, es aquélla una disposición de espíritu excepcional y rara". 38 
En fin, en donde "Andrenio" más se aparta de Valera es en creer con Reyles que no está bien poner vallas al campo del novelador; esto ya es mucho, aunque dista de ser la completa vindicación del uruguayo que han querido ver en ello los amigos de éste.

VII

Con un brío que mal cuadra con la desinclinación que declara sentir, 39 la "siempre ecuánime y sagaz doña Emilia" 40 entra en la palestra de El Liberal el 31 de octubre. Descartando, como dice, "lo que se refiere al literato uruguayo don Carlos Reyles, a su libro Academias y a su artículo publicado en El Liberal", para mayor desembarazo se limita a lo fundamental. Encuentra que son tres los puntos suscitados por Valera: "que en literatura no cabe progreso y no debe haber modas; que no conviene imitar lo moderno ni lo extranjero, sino lo antiguo y lo castizo, 41 y que las novelas modernas no son para descalzar a las antiguas".

Respecto a que no hay progreso en el arte, doña Emilia se muestra enteramente persuadida. $Y$ hay que confesar que, con la sensatez que la caracteriza, sabe apoyar esta opinión con razones más convincentes que las del mismo Valera: "Las artes no adelantan gradualmente, como las ciencias y la industria. Claro es que en la historia del arte se registran también períodos de atraso..., y que desde la informe canción... de una tribu de la Polinesia, hasta las odas de Píndaro..., hay una larguísima escala que recorrer; pero la capital diferencia entre la ciencia y el arte, consiste en que el arte se desarrolla como los organismos..., mientras la ciencia crece por yuxtaposiciỏn, no gasta ni consume el caudal adquirido..., y los siglos acendran y acrecientan su tesoro. El progreso científico suele guardar proporción con los esfuerzos realizados, y el de las artes no depende tanto del esfuerzo como de las circunstancias felices y las aptitudes del individuo genial. En determinado momento, cierta nación ve nacer a cierto sujeto capaz de comtinicar al arte maravilloso impulso, y aunque la humanidad progrese, no aumentan las probabilidades de que nazca otro sujeto así, por lo cual... ningún dramaturgo podrá alardear de medirse con el autor de Otelo... Hay, 
sin embargo, en el arte y en la poesía algo que progresa; pero es lo que podemos llamar su doctrina y su técnica. Preguntad a los entendidos en pintura, y os dirán que ogaño se pinta más que antaño, que la factura se domina más... Esto concurre a demostrar la verdad del aserto de Valera: lo que progresa en arte y en literatura es el elemento científico, lo que pide atención, estudio y esfuerzo". 42

En cuanto a las modas: "Aquí empiezo a disentir del respetado preopinante... Valera llama severamente modas a lo que yo llamaría estilos, maneras, revoluciones y evoluciones, considerando que las hubo siempre, y siempre seguirá habiéndolas, precisamente porque no se concibe la fijeza e inmovilidad del ideal estético, y de las variaciones que todo sufre no se eximiría la literatura sino petrificándose. 43 ...Quítele Valera a la palabra moda su acepción femenil, y verá cómo ya no le molesta... Parece desprenderse del texto de Valera que este achaque de las modas literarias es peculiar de nuestro siglo. Yo confieso que al leer los autores clásicos, encuentro en ellos, cuanto más remoto el tío del tiempo, más semejanzas, más aire de familia... Lo externo, lo que viene de fuera, el ajeno pensar y sentir, se sobreponía más entonces que ahora a la verdadera originalidad, que es una fuerza individual".

Disintiendo así poco a poco y muy hábilmente, llega la egregia escritora a defender la imitación, no la servil que encuentra en el pasado, sino la involuntaria de que nadie se exime en ninguna edad: "No existe libro bueno sin precedentes, sin una cantidad incalculable de tradición y de involuntaria reproducción... El bárbaro no deja de producir hermosas obras de literatura por bárbaro, sino porque le rodean otros bárbaros y le precedieron infinitos". En cambio doña Emilia se empadrona con Valera y Gómez de Baquero al reprobar "la falta de discernimiento y sobra de servilismo en imitar a los autores de moda. A menudo se imita en ellos, no su chispazo genial, ni aun su retórica propia, sino sus muletillas y estribillos, sus tópicos y extravagancias".

Verdadera defensa de la materia de la nueva literatura no la hay en esta carta de la escritora, ni en la que añadió días después. Tal defensa la había emprendido ya en 1887 al tratar del naturalismo en La cuestión palpitante, cuyas conclusiones están admirablemente condensadas en la cita con que terminamos este estudio. En su segunda carta de El Liberal, sólo vuelve a argüir con igual penetra- 
ción que: "No hay progreso, no hay mejoramiento; hay variación y evolución continua. Inútil oponerse a ella: la victoria de un arte nuevo es fatal e irremediable; durará lo que dure, pero llega siempre". No cree con Valera que el arte nuevo no tenga realmente existencia. Al contrario, tan convencida está de que en efecto la tiene, de que la novela ha cambiado en su más íntima esencia, que llega a preguntarse si no ha dejado de ser novela, pregunta que ya parece haber hecho Jacinto Octavio Picón en su carta, que desconocemos. 44

VIII

Ya viejo, casi ciego, el benemérito Eduardo Benot añade su voz al certamen en carta a El Liberal, fecha de 21 de noviembre de 1897. "En cuanto a la esencia de la cuestión estoy enteramente con el señor don Juan Valera", escribe. "Creo que no existe, ni puede existir, artificio ni procedimiento ninguno para hacer novelas, como quien fabrica puntas de París o gruesas de corchetes". Ahí, pues, cree ver la esencia de la disputa. Luego en Reyles tenemos un hombre que busca la fórmula preciosa que convierte en oro sus palabras. Esto, al menos, es lo que se deja entrever por los párrafos de Benot, no siempre muy coherentes. $\mathrm{Y}$ es una actitud que el sabio encuentra reflejada a menudo en "ciertas novelas a la moda, que, a pesar de lo bruñido de la factura y lo esmerado del estilo, dejan, sin embargo, ver demasiado a las claras que son artificiales y contrahechas". Para Benot, como para Valera, la gran creación es fruto de grandes dotes: "En las obras del genio, lo primero es el genio". En lo demás, antes se coloca Benot con Reyles que con el autor de Pepita Jiménez. $\mathrm{Su}$ insistencia sobre lo imprescindible del numen no excluye el progreso gradual. Y más explícitamente da a entender que, una vez que nazca el escritor con las dotes suficientes, es lo de menos la materia en que las ejerza. No todos los autores se inclinan por naturaleza a tratar los mismos asuntos: "El novelista, pues, necesita, no solamente haber nacido para ello, sino con el grado de energía que reclama la clase de ficciones a que su personalísima aptitud lo impulse". $Y$ acepta sin protestar la invasión por la novela de todos los campos, y el incremento que ha tomado el realismo: "Hoy la novela tiene absorbidos todos los géneros... y hoy lo abarca todo, porque el hombre moderno goza con interés embriagador, no contemplando los re- 
tratos de la realidad, sino saboreando la ficción encarnada consubstancialmente en la íntima observación de lo próximo y real". Benot, pues, a pesar de su profesada adhesión a la causa de Valera, se alía en la práctica con el adversario de éste.

Igual ocurre con José Navarrete, novelista de la época, y de tan infina categoría que apenas halla cabida en el centón del padre Blanco García. E1 12 de diciembre aparece su carta, también en las planas de $E l$ Liberal, en la que, antes que referirse a la contienda ReylesValera, expone sus creencias en materia de arte. Muéstrase naturalista atenuado, gran admirador de Zola: "Como no hay hermosura ni nada fuera de la Naturaleza, es preciso ser naturalista en punto a concepciones artísticas; pero no ha de confudirse el naturalismo, el realismo, con el materialismo... El defecto capital de la escuela realista es lo que tiene de materialista; es olvidarse del naturalismo del alma y del naturalismo de la razón, de los cuales no ha prescindido Zola en su admirable Teresa Raquin". De Le roman expérimental del francés adopta la función que atribuye al arte de propagar las ideas científicas: "Las abstracciones de la ciencia no llegan a la vida de los pueblos sin pasar por los dominios del arte... E1 progreso no cunde alli donde viven divorciados la ciencia y el arte". Y quiere hacer cuadros en que aparezcan la "copia fiel de la sociedad contemporánea, fotografías del mal, o ideales posibles del bien..., formando libros que hagan pensar y sentir tan hondo, que de tal suerte alumbren la razón de los lectores y los conmuevan..." Es decir, que, salvo exagerar el prurito docente, Navarrete francamente apoya la actitud de Reyles. Su "pensar y sentir tan hondo" son eco de las palabras de éste. $Y$, aunque cae en cierta ambigüedad al dictaminar que "hay que combatir con rudeza el arte de puro recreo, el arte por el arte", es lo probable que estuviera pensando en el andaluz, cuya frivolidad ya había atacado el uruguayo.

\section{IX}

Con Navarrete parece agotarse la polémica, llevando Carlos Reyles, en casi todas las opiniones, la palma en el debate. En las batallas entre antiguos y modernos, la victoria es siempre de éstos. La victoria, sí. ¿Y la razón? Eso ya es harina de otro costal. Aunque aquí también cabría decir que sí, que la razón también la tienen los 
modernos, mejor dicho, se la toman. Voltaire y Moratín, jueces nada despreciables, encontraron insoportables ciertos aspectos, muy apreciados posteriormente, del teatro shakesperiano. $\mathrm{Y}$ no se equivocaban, como tampoco nos equivocamos los que disentimos de su fallo. Si hay una sola verdad incontrovertible en el mundo de la estética, es que no cabe legislar sobre la forma y el contenido artísticos. $Y$ si hay otra, dicho sea entre paréntesis, es que nunca se dejará de legislar precisamente sobre esa materia. Sirvan de ejemplo Valera y Reyles.

Pero si Reyles en este aspecto de su pensamiento por fuerza llevó consigo a la opinión crítica, luego vinieron otros críticos, entre ellos algunos compatriotas del autor, a reconocer que anduvo errado en las academias, y por los motivos que expuso Valera. Al hablar de Primitivo, Zum Felde comenta: "Conviene observar aquí que, buscando ser más original y sutil, Reyles aparece en esta novelita bastante más ingenuo. Es evidente que su personalidad sufre un trance de sugestión". 45 Un poco más adelante: "En verdad, $E l$ extraño ha sido sólo un momento de desvío sugestivo en la vida intelectual de Reyles, algo como una aventura fuera de la órbita normal de su personalidad. El carácter propio y permanente de Reyles -así en la literatura como en la vida- es el realismo; toda su obra, descle Beba hasta El embrujo de Sevilla y con la sola interrupción de las Academias se ajusta a esa sensibilidad y a ese concepto realistas que son su imperativo temperamental". $46 \mathrm{Y}$ al llegar a La raza de Caín, de un Reyles ya vuelto al recto camino, llama a las academirs "su extravío de la víspera". 47

O. Crispo Acosta ya había expresado un dictamen comparable: " 'Ultima moda de París' llamó don Juan Valera a la obrita de Reyles, y si es justo rechazar en su pulla ingeniosa la nota de frivolidad que zahiere, es también justo proclamar la especie de adivinación que hay en ella. Estaba don Juan Valera algo atrasado en sus informaciones sobre las novedades literarias de París; nada sabía de Maurice Barrès; pero acertó con buen tino cuando, ignorando la influencia directa de éste sobre $E l$ extraño, señaló la ascendencia de Paul Bourget a la escuela de Reyles". 48 De la misma manera Torres-Rioseco, gran admirador de Reyles pero fino crítico por encima de toda admiración, observa que Reyles "pasa por un periodo de imitación y encuentra su camino de Damasco y su verdad - rea- 
lismo y violencia de expresión- en sus dos últimas novelas". 49 En el prólogo a El terruño, 50 José Enrique Rodó viene a decir casi lo mismo: "Querer ganar la originalidad rompiendo de propósito toda relación con el mundo a que se pertenece, conducirá a la originalidad facticia e histriónica, que casi siempre oculta el remedo impotente de modelos extraños, 51 no menos servil que el de los próximos; pero nunca llevará a la espontánea y verdadera originalidad personal, que, como toda manifestación humana..., tiene también base social y colectiva, y no es sino el desenvolvimiento completo y superior de cierta cualidad de raza, de cierta sugestión del ambiente o de cierta influencia de la educación... 52 Alegrémonos, pues, de que el escritor de la significación de Carlos Reyles siente esta vez su garra en el terruño nativo... 53 Así este ilustre novelista nuestro, después de ganar personalidad completa y fama consagrada, por otros caminos que los de la realidad característica del terruño, viene a esta realidad..." 54

Coincide, pues, la opinión general de un modo más o menos explícito en que Reyles, en una época, fué culpable de la "más ruin y espantosa de todas las herejías, en la religión del arte" de Valera. Reyles no lo confesó nunca. Al contrario, años más tarde en su Arte de novelar todavía alude con petulancia a la crítica del andaluz. 55 Modificó su práctica no obstante, haciendo amplia penitencia por su herejía. Y la hizo precisamente alejándose de los franceses, aunque sin dejar de leer a éstos y a los vanguardistas de otroś países. Cabe añadir que al hacerlo se acercaba, sin imitar, cada vez más a los mal traídos Pereda y Galdós, y aun a Cervantes. 56

El propio Reyles, en el mismo Arte de novelar, fruto de su madurez artística y crítica, acaba señalando la naturaleza pasajera de los pronunciamientos literarios cuando, después de seguir muty de cerca en $B e b a$ el procedimiento de Zola, 57 confiesa que "el famoso documento humano de Zola nos hace sonreír, y la misma observación científica, llamémosla así, amaina en sus pretensiones'. $58 \mathrm{Y}$ cuando ya fué novela del pasado la novela del porvenir, motivo de sus psalmos en días más ingenuos, reconoció la futilidad de buscar al Mesías en los noveleros: "Pero se exagera. La creación desterró totalmente a la realidad en vez de servirse de ésta como de un trampolín; el sentimiento a los hechos; los personajes ficticios, arbitrarios, a los auténticos; la psicología imaginaria, a la psicología 
positiva; la contemplación de un mundo voluntariamente estrafalario, a la acción, que es la vida, y la novela, a pesar de los descubrimientos de Proust, Lawrence, Huxley, Joyce, las sutilezas de Gide y Giraudoux y los aportes de Morand, Mauriac, Delteil, Samson, Larbaud, Radiguet, Soupault, Montherlant, Supervielle, Celine, Faulkner, Malraux y muchos otros que traen algo nuevo, se hizo poco probable, poco creíble, perdió vida, interés, dinamismo, siendo ella de por sí tanto vida como arte. Se anemió, dejó de ser novela". 59

Haya o no haya progreso, las letras no se estancan por mucho tiempo. No saldrá falso profeta el que vaticine nuevos Pérez de Ayala y Reyles que se inspiren en el Quijote, nuevos Güiraldes que resuciten la novela picaresca, nuevos Proust que creen nuevas modalidades literarias. Los antiguos, mientras tanto, seguirán con sus dudas. Ya lo dijo Yeats en nuestro epígrafe. $Y$ del dudar al condenar, ya se sabe, hay poco trecho. De ahí que surgirá siempre la cuestión del progreso, 60 negado con razón por los antiguos, defendido con igual ahinco y razón por los modernos; buscando éstos su defensa en la actitud y la materia de su arte nuevo, fuente precisamente de la sumaria de aquéllos; y olvidados unos y otros de una gran verdad, nunca mejor expresada que por la Pardo Bazán, y que no por ser una verdad como un templo menos merece citarse (al fin ocurre a menudo que son los templos lo más digno de atención en cualquier horizonte): "La belleza literaria, que es en cierto modo eterna, es en otro eminentemente mudable, y se renueva como se renueva la atmósfera, como se renueva la vida". 61

\author{
EDWIN S. Morby, \\ University of California.
}

\title{
NOTAS
}

1 En la Historia sintética de la literatuta utuguaya, I, Montevideo, 1931. Véanse las pp. 19-22 del ensayo.

2 Novelistas contempotáneos de Amética, Santiago de Chile, 1939, pp. 311-351. Véanse las pp. 314-315.

3 Incitaciones, Santiago de Chile, 1936, pp. 46-48.

4 Montevideo, s. a. (1896). 
5 Primitivo, p. 7.

$6 \quad$ Ibid., p. 9.

7 Obras completas, XLIII, Madrid, 1916, pp. 238 ss.

8 Ibid., pp. 242-243.

9 Ibid., p. 239.

10 Ibid., p. 242.

11 Ibid., p. 250.

12 Ibid., pp. 250-251. Conviene fijarse bien en esta opinión de Valera, que le absuelve completamente de la acusación de Guillot Muñoz (op. cit., p. 22) de haber defendido en la novela "un trotecito de "mero solaz y entretenimiento"." Las palabras solaz y entretenimiento hemos visto además que las tomó Valera de Reyles. Este las emplea para describir un arte para él anticuado: Valera las utiliza para impugnar la doctrina de Reyles, pero dándoles un sentido muy otro, y nada frívolo.

Se ha repetido hasta el tedio la aplicación del adjetivo "clásico" a Valera. Tal vez no cabe mejor prueba de la justicia del término que la pregunta que Valera se hace (p. 254) y la contestación que luego ofrece: “¿Por qué me han de repugnar las atrocidades y los crímenes en novelas y dramas, cuyos personajes son mis contemporáneos, y no han de repugnarme ni Medea..., ni Mirra..., ni Pasifae...?" Es to probable que esos casos anormales y excepcionales le sean más aceptables a medida que revistan más el carácter de mitos y ejemplos universales, $y$ se alejen de lo actual e individual, aunque en el fondo no sean menos: "monstruosidades y anomalias enfermizas, posibles aunque raras, por dicha, en la naturaleza humana" ( $\mathrm{p}$ 252). No es ésta exactamente la explicación que da: Valera, pero acaso llegue a ser la misma. De todos modos, es la actitud clásica, mientras que la contraria de Reyles coloca a éste en cierta manera dentro del romanticismo, mal que le hubiera pesado zeccnocerlo.

13 Ibid., p. 256.

14 Guillot Muñoz, op cit., p. 20: "Valera, después de hacer el elogio de 'Primitivo'...."

15 Obras completas, XLIII, p. 242.

16 "El extraño", última moda de Paris, en Obras completas, XXIX, pp. 109-119. Esta cita es de la p. 110. Es muy interesante ver que el gran dramaturgo y crítico irlandés, William Butler Yeats, se expresó en términos muy comparables: "The scientific movement is ebbing a little everywhere... and" $I$ am certain that everywhete literature will return once more to its old extravagant, phantastical expression, for in literatute, unlike science, there are no discoveties, and it is always the old that tetutns"; citado por Thomas H. Dick- 
inson, en An Outline of Contempotaty Drama, Houghton Mifflin Company, 1927, p. 210 . A Yeats le preocupaba grandemente el tema. Compárese: "In litetature also we have had the illusion of change and progress, the art of Shakespeare passing into that of Dryden, and so into the prose drama, by what has seemed when studied in its details unbroken progress". Essays, New York, 1924, p. 279. Aunque Yeats, por otra parte, fué miembro, y hasta portaestandarte de una "escuela" literaria de las conscientes.

17 Obras completas, XXIX, p. 112. Compárese la opinión de Rafael Altamira: "Lo nuevo puede ser bueno; pero no por ser nuevo, sino por otras cualidades que es preciso aquilatat con el mismo rigor que para la crítica de lo viejo se usa", psicología y literatura, Barcelona, 1905, p. 122.

18 Ibid., p. 113.

19 Ibid, p. 114.

20 Merece notarse que Valera, además đe criticar El ex̃traño en El Liberal, lo comenta en los mismos términos en su carta del 4 de agosto de 1897 a la Revista ilustrada de Nueva York; véase el tomo IV de sus Cartas ameticanas (Obras completas, XLIV), pp. 144 y sigs.

21 Arte de novelar, en Incitaciones, Santiago de Chile, 1936, pp. 43-62. La cita que va a continuación es de las pp. 54-55.

22 No deja de llamar la atención el parecido entre el pensamiento de este ensayo de Reyles y el del tomito de Ortega y Gasset, La deshumanización del arte, Madrid, 1925. Probablemente se debe esta coincidencia de ideas al hecho de que dos finos criticos, al tratar un mismo problema, no pueden menos de concurrir en sus conclusiones generales. Por otra parte, conviene observar que en el párrafo citado se encuentran algunas afirmaciones que Reyles no habría hecho en la época de que tratamos. Ya se verá cómo modificó su actitud.

23 "Influye mucho en la novelería el concepto clásico, y ya rectificado, del progreso, como una setie cronológica e intertumpida de estados. Si esto fuera así, tanto en la civilización general como en las direcciones concretas de la actividad humana, clato es que la perfección de la vida y de los conocimientos estaria en relación directa con los años, y 10 mejor sería siempre 10 más re-. ciente, más bien, lo actual, cuyo reinado dependeria de lo futuro. Pero no ocurre así en la realidad. Aparte de que la idea de progreso supone un ideal fijo de perfección, que puede ser equivocado, lo cierto es que los hombres no recorren en línea recta el camino que a ese ideal conduce...", Rafael Altamira, op cit., pp. 119-120.

24 Obras completas, XXIX, pp. 133-142.

25 Ibid., p. 135.

26 Ibid., pp. 143-181. 
27 Ibid., pp. 156-158. Compárese: "Ante las figuras de ceta todos hemos sentido una peculiar desazón... Y concluimos por sentir asco hacia aquella especie de cadáveres alquilados. La figura de cera es el melodrama puro", J. Ortega y Gasset, op cit., pp. 44-45. Claro que la imagen de Valera encierra un sofisma más o menos evidente; y es la de suponer inalterable el ideal estético. Además, no se trata de gustar a Pericles. Otra prueba del clasicismo esencial de Valera, y, diría Ortega, respecto al propósito de Reyles de compungit a sus lectores, de lo que éste distaba de penetrar al fondo de la estética: "Alegrarse o sufrir con los destinos humanos que, tal vez, la obra de arte nos refiere o presenta, es cosa muy diferente del verdadero goce artístico [el solaz y pasatiempo de Valera]. Más aún: esa ocupación con lo humano de la obra es, en principio. incompatible con la estricta fruición estética", op. cit., p, 18.

28 Obras completas, XXIX, p. 170.

29 Es muy sensible la falta de los artículos de Picón y Alas, indudablemente entre los más sugestivos de todos, y que no he podido encontrar hasta ahora.

30 "La polémica terminó con el fallo de Gómez de Baquero, quien dió la victoria a Reyles", Guillot Muñoz, op cit,, p. 22; "En esta polémica intervinieron Emilia Pardo Bazán, Leopoldo Alas y por fin Gómez de Baquero, y éste último dió toda la razón a Carlos Reyles", Torres-Rioseco, op. cit., p. 51. Torres recogió sus datos de boca del propio Reyles, lo que hizo también Guillot Muñoz. Se comprende que Reyles, muchos años después de este episodio de su juventud, no haya tenido muy presentes los detalles.

31 La España Moderna (Madrid), febrero de 1897, p. 145.

32 Ibid., pp. 145-146.

33 La España Moderna, abrîl de 1897, p. 135.

34 La España Moderna, junio de 1897.

35 La España Moderna, octubre de 1897, p. 135. El artículo ocupa las pp. $135-140$.

36. Ibid., p. 137. Sabido es que Unamuno se colocaba en un punto de vista más cercano al de Valera, reiterando una y otra vez sibilinos anatemas contra la ciega y funesta adoración de París. Bastará citar el pasaje en que se dirige a los hispanoamericanos sobre "la fascinación que sobre ellos ejerce París, como si no hubiese otra cosa en el mundo y fuera el foco, no digo ya más esplendente, sino único, de civilización. Es manía que he combatido muchas veces, encontrando para ello fuerzas en la manía contraria de que acaso estoy aquejado. Pues no he de ocultar que padezco de cierto misoparisienismo, que reconociendo lo mucho que todos debemos en el orden de la cultura a Francia, estimo que lo parisiense ha sido, en general, fatal para nosotros", Contta esto y aquello, Madrid, 1912, p. 14. Unamuno habría preferido la imitación de 
otros países: "En España, por regla general, lo que es de imitación inglesa o italiana, resulta más español, más propio y, por lo tanto, más hermoso que lo de imitación francesa", ibid., p. 247.

37 La España Moderna, octubre de 1897, p. 138.

38 Ibid., p. 139. "El personaje que presenta el escritor uruguayo en El extraño es un tipo refinado y complejo, que pertenece a la familia de los héroes de Bourget y Marcelo Prevost...", ibid., p. 138.

39 "Por mil razones que ahorro, no gusto de polémicas literarias..."

40 Unamuno, Ensayos, VII, p. 194.

41 Punto es éste que dejamos sin desarrollar, aunque no deja de tener gran interés. Opina Valera que de lo antiguo sobrevive lo bueno solamente, lo que es digno de imitarse, mientras que el imitar lo nuevo encierra grandes peligros. Por ejemplo, fácilmente podría darse el caso de imitarse algo que cayera pronto en el olvido, o pareciera ridiculo. Ya se verá que Reyles mísmo se dió cuenta más tarde de este escollo, bastante evidente además. A doña Emilia le parece que, al contrario, del pasado sobreviven muchas cosas mediocres.

42 Compárese lo que dice Ortega y Gasset sobre la importancia del genio individual: "Es gana de hacerse vanas ilusiones y de eliminar cómodamente la cuestión, suponer que la creación artística depende sólo de esa capacidad subjetiva $e$ individual que se llama inspiración o talento", op. cit., p. 85.

43 "En cada época hay una moda literaria dominante, una escuela, y sucede que aquéllos que la siguen y cultivan se creen más originales que aquéllos otros atenidos a antiguas modas o escuelas. En realidad no son sino más 'modernos', en el sentido etimológico de esta palabra, es decir, más de moda". Unamuno, Soliloquios y conversaciones, Madrid, 1911, p. 147.

44 "La novela ha sido la forma característica y preferida de la retórica moderna; que por su riqueza y variedad, y por los nombres geniales que en ella descollaron - así como por el ancho campo de abrió a todas las direcciones del sentimiento y del pensamiento, y que justifica las dudas de Jacinto Octavio Picón al preguntarse si son realmente novelas las que calificamos de tales- es la novela, o lo que recibe este nombre, el timbre más preciado de las letras modernas, su foco de vida más intenso. La gloria de la novela ya empieza a declinar, su estrella palidece; y si, en efecto, rindiésemos parias a la moda, hoy deprimiríamos a la novela, género que ya no contenta a los snobs parisienses y que declaran anticuado - cuando precisamente va a ser clásico". Ortega y Gasset también ve la novela en decadencia: "En suma, creo que el género novela si no está irremediablemente agotado se halla en su período último y padece una tal penuria de temas posibles que el escritor necesita compensarla con la exquisita calidad de los demás ingredientes necesarios para integrar un cuerpo de novela", op. cit., p. 89. Aunque cree este autor que precisamente por estar en decadencia la novela está destinada a producir sus más bellas manifesta- 
ciones. El propio Reyles, como se verá más adelante, llegó a constatar que la novela en un momento había dejado de serlo. Claro que esta opinión está lejos de ser propiedad exclusiva de los autores citados, siendo, como es, casi un lugar común.

45 Proceso intelectual del Utuguay, II, Montevideo, 1930, p. 270.

46 Ibid., p. 273. "It is not permitted to a man, who takes up pen or chisel, to seek otiginality...", W. B. Yeats, Pet amica silentia lunae, New York, 1918 , p. 44.

47 Ibid., p. 274. Estos juicios se encuentran ya expresados por el propio Zum Felde en su Crítica de la litetatuta uruguaya, Montevideo, 1921. Véanse las pp. 179-181.

48 Lauxar, Carlos Reyles, Montevideo, 1918, p. 62.

49. Op. cit., p. 329.

50 Edición retocada y definitiva, Madrid, s. a. El prólogo está firmado en marzo de 1916.

51 “. . no han sabido ver la vida que alli, en torno de ellos, se desarrolla. $Y$ no faltan los que ven y juzgan a su propio país a través de Europa $y$, lo que es peor, de libros europeos. Y así es difícil llegar a la originalidad literaria", Unamuno, Ensayos, VII, p. 139.

52 El tertuño, pp. x-xi.

53 Ibid., p. xiv.

54 Ibid., p. xv.

55 En el tomo Incitaciones, citado arriba. Véanse las pp. 46-48, en que resume la actitud que adoptó frente a Valera.

56 "Quiero apuntar aquí el beneficio que ha reportado a este autor el estudio de los clásicos españoles y de algunos novelistas de fines de siglo como Valera, Pereda y Galdós. Del Quijote no sólo hay puntos de estilo que convendría estudiar sino también episodios y situaciones. Algo de Don Quijote tiene Tocles y mucho de Sancho Panza la utilitaria y prosaica Mamagela", dice Torres al hablar de El terruño; op. cit., p. 338.

57 Véase Torres-Rioseco, op. cit., p. 321.

58 Incitaciones, p. 55 .

59 Ibid., p. 59.

60 Valera se acerca mucho a la idea de la más autorizada crítica contemporanea sobre el progreso en literatura, idea bien condensada por Lascelles Abercrombie: "But when I speak of a forward movement, it will not, I hope, be 
supposed that I mean a process by which literature is continually getting better and better... Yet the advance of literature towards perfection has been proclaimed several times; though it would not be easy to say what perfection here can mean; not is it necessary for the word progress to mean anything more than the capacity for change implicit in the nature of a thing becoming gradually explicit in its continual adjustment to circumstance. The notion, it is true, that literature is improving, has usually been based on a short view of things; but that has not prevented it from being very positively assetted...", Progtess in Literature, Cambridge University Press, 1929, pp. 23-24.

61 La cuestión palpitante (Obtas completas, I) Madrid, 1891, p. 284. Es realmente notable descubrir que doña Emilia creía ser ella y no Reyles ocasión de la polémica que acabamos de resumir (aunque verdad es que algún motivo tenía para pensar así, después de los cambios de opinión que surgieron a raíz de la aparición de La cuestión palpitante): "El haber profesado de un modo explícito esta verdad -que el quid del arte no es racional sino instintivo-, fué uno de los mayores aciertos críticos de Valera. La sostuvo en sus artículos titulados "Sobre la novela de nuestros días" y "Del progreso en el arte de la palabra", dándose el curioso caso de que, al sostenerla, creia impugnarme a mi, que pienso exactamente lo mismo, que he negado a rajatabla los adelantos de arte, la evolución de altura, reconociendo sólo la evolución de diferenciación y de adaptación al ambiente o medio". Retratos y apuntes litera. rios (Obras completas, XXXII), Madrid, s. a., pp. 234-235. 
